Article

\title{
Continuous Detection of Diurnal Sodium Fluorescent Lidar over Beijing in China
}

\author{
Lifang Du ${ }^{1}$, Jihong Wang ${ }^{1}$, Yong Yang ${ }^{2}$, Yuchang Xun ${ }^{1,3}{ }^{-}$, Faquan $\mathrm{Li}^{2}$, Fuju $\mathrm{Wu}^{1,4}$, \\ Shunsheng Gong ${ }^{2}$, Haoran Zheng ${ }^{1}$, Xuewu Cheng ${ }^{2, *}$, Guotao Yang ${ }^{1}$ and Zhenghua Lu ${ }^{1,4}$ \\ 1 State Key Laboratory of Space Weather, National Space Science Center, Chinese Academy of Sciences, \\ Beijing 100190, China; lfdu@nssc.ac.cn (L.D.); jhwang@nssc.ac.cn (J.W.); ycxun@swl.ac.cn (Y.X.); \\ wufuju17@mails.ucas.ac.cn (F.W.); hrzheng@spaceweather.ac.cn (H.Z.); gtyang@nssc.ac.cn (G.Y.); \\ lzh_cas@163.com (Z.L.) \\ 2 Wuhan Institute of Physics and Mathematics, Chinese Academy of Sciences, Wuhan 430071, China; \\ yangyong@wipm.ac.cn (Y.Y.); lifaquan@wipm.ac.cn (F.L.); gongss@wipm.ac.cn (S.G.) \\ 3 College of Physics and Optoelectronics, Taiyuan University of Technology, Taiyuan 030024, China \\ 4 University of Chinese Academy of Science, Beijing 100049, China \\ * Correspondence: lidar@wipm.ac.cn; Tel.: +86-27-87197107
}

Received: 21 November 2019; Accepted: 17 January 2020; Published: 20 January 2020

\begin{abstract}
Based on application of the atomic filter technology in a signal detection system of lidar, the diurnal observation of sodium lidar were obtained using the system at the National Space Science Center of the Chinese Academy of Sciences at Beijing Yanqing station $\left(40.5^{\circ} \mathrm{N}, 116^{\circ} \mathrm{E}\right)$ in April 2014. During the lidar observation period, among the 103 cases of continuous daytime observations, the longest time was $181 \mathrm{~h}$. In the case of a continuous observation period of 5 days (13-18 October 2014), the signal-to-noise ratio reached to 19:1 at 12:00-13:00 Local Time of the daytime, when the spatial and time resolutions were respectively set to $96 \mathrm{~m}$ of $167 \mathrm{~s}$. The improvements resulted in the highest detection level of any existing diurnal lidars in China. Some interesting phenomena such as the sporadic sodium layer have also been observed during the daytime. The daytime capability extended the observing time range of the earlier systems that were limited to only nighttime observations. This innovation provides a useful method for the studies of diurnal tides, photochemistry, gravity waves, and correlative modeling studies.
\end{abstract}

Keywords: sodium fluorescent lidar; daytime observation; atomic resonance filter technique; sporadic sodium layer; continuous diurnal observation

\section{Introduction}

Between 80 and $110 \mathrm{~km}$, there is a metal atom layer including sodium, potassium, and calcium, among which sodium lidar has been widely developed due to the sodium atomic high density on the one hand, and on the other its high resonance fluorescence efficiency [1-5]. At present, sodium fluorescence lidar technology cannot only detect the density of sodium layer, but also measures the wind and temperature in the middle atmosphere [6-10]. However, most of the sodium lidar in the world can only work at night to avoid the strong solar background light noise during the day. Parameters of the middle and upper atmosphere are measured by analyzing the back-scattered photons from the atmosphere [11,12], and received signal is very weak, and hence implementation of a single photon counting mode is required. Especially during the daytime, the strong sunlight influences the signal-to-noise ratio (SNR) of lidar data. Thus, in the early stages of lidar technology development, lidar observations could only can be carried out at night (Local time is about 19:00-5:00), relying on the narrow-band interference filter technology. 
However, full-diurnal cycle observation data are needed for both space scientific research and space environment exploring studies. Ultra narrow band filter components, such as F-P interferometer, had been used in the lidar system to suppress background light. In 1982, the F-P etalon was implemented in the sodium lidar developed in Brazil [13]. In 1987, effective diurnal observation data of the sodium layer had been obtained with F-P etalon in USA [14]. The basic principle of F-P interferometer is optical interference, and the bandwidth of transmission peak can be a few picometers to tens of picometers. Nevertheless, narrow band interference filters are used to suppress other auxiliary transmission peaks. Thus, the out-of-band suppression ratio is generally not high enough, and the fields of view are very small. When F-P is employed to the lidar system, the laser beam needs to be highly collimated, and a relatively smaller field of view has to be achieved. Although the design of transmission at sodium wavelength is convenient, stability of transmission peak is poor due to the restrictions of ultra narrow bandwidth requirements of the receiver. In practice, transmission peak shift is not easy to control, and accurate temperature control and effective vibration reduction are needed to enable long-term lidar observations.

In 1988, the atomic resonance filter technique was proposed [15]. Although the stability and ultra narrow band improved, this kind of filter has not been widely used due to its low quantum efficiency (less than 10\%) that further reduces the extremely weak lidar signal. In 1991, a new method based on atomic Faraday anomalous dispersion filter technology (FADOF) was developed [16]. Effective transmission of this atomic resonance filter is greatly improved, along with higher stability and ultra narrow band characteristics. Theoretically, it can be higher than $90 \%$ for polarized lights. This technique was implemented in the sodium lidar successfully [17-19], with the first continuous high SNR lidar observations of the sodium layer. This innovation provides a novel method for the studies of diurnal tides, photochemistry, gravity waves, and other correlative modeling studies [20-23].

In China, the research based on atomic filter technology has been carried out in Wuhan Institute of physics and mathematics (WIPM), Chinese Academy of Sciences. A series of atomic filters and discriminators for different materials and wavelengths have been developed [24,25]. And they have advantages of narrow transmission band, high out-of-band suppression ratio, stable transmission characteristics, wide field-of-view and high transmission rate. These atomic filters and discriminators have been employed in laser communication, Doppler wind lidar [26], chromatography of the sun [27], and solar magnetic field and velocity field [28]. Especially in 2006, the sodium atomic filters have been employed for daytime observation of sodium fluorescence lidar [29], and diurnal observation of the sodium layer, achieving the first daytime observation in China [30,31]. However, such diurnal observations are limited, and to improve the statistics, daytime sodium lidar was developed at Yanqing lidar station in Beijing in 2014, under the joint research and development by the National Space Science Center of the Chinese Academy of Sciences (NSSC) and WIPM. In view of the good observation conditions of Yanqing station, the sodium fluorescence lidar obtained good data during the day, the SNR of daytime signal is much better than that of the previous instruments. In addition, under good weather conditions, continuous observations are possible throughout the day, with the longest data sets up to 7 days, which improve our current understanding of the middle and upper atmosphere.

\section{Diurnal Sodium Fluorescence Lidar System}

The diurnal sodium fluorescence lidar system is built on the basis of the meridian project Beijing Yanqing site. This lidar is a dual-wavelength simultaneous detection system, which can simultaneously either detect sodium and potassium, or simultaneously detect sodium and Rayleigh [32]. In order to implement the full-diurnal cycle observation of sodium layer, a dual-channel Faraday anomalous dispersion optical filter (FADOF) was added to the signal detection system, and the corresponding linewidth compression technology was adopted in the laser emission system. The whole structure schematic diagram of lidar system is shown in Figure 1. 


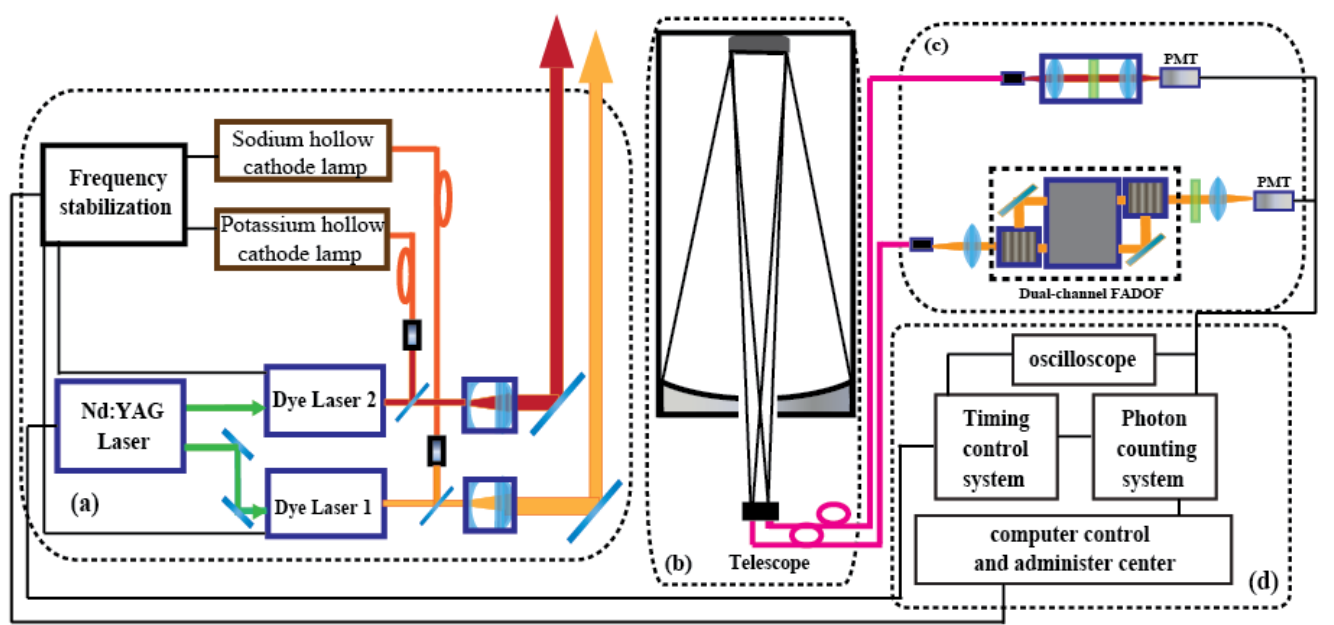

Figure 1. Schematic diagram of diurnal sodium fluorescence lidar system (dual-wavelength lidar detection system). A lidar system is composed of (a) a laser emission system, (b) a signal receiving system, (c) a signal detection system, and (d) a data acquisition and timely sequence control system.

The laser emission system is composed of a pulsed Nd:YAG laser, two pulsed dye lasers, two laser beam-expanding telescopes, two high power beam splitters, two high power laser mirrors, two reflective devices equipped with a precision stepping motors, two hollow cathode lamps (HCL), and a frequency stabilization system. This system used secondary frequency doubling technology and residual light recovery technology to produce two laser beams with wavelengths of $532 \mathrm{~nm}$ each. Firstly, the fundamental frequency $1064 \mathrm{~nm}$ laser generated by the Nd:YAG laser passed through a frequency-doubling crystal (DKDP) and generated the initial $532 \mathrm{~nm}$ laser through the I-type frequency-doubling method. This laser beam then passed through a dichroic mirror and became separated from the original $1064 \mathrm{~nm}$ laser, from which a $532 \mathrm{~nm}$ laser was reflected. The remaining laser was input into the second piece of frequency doubling crystal (DKDP), and a II-type frequency doubling was used to generate the second beam in order to meet the polarization demand of the laser, resulting in two $532 \mathrm{~nm}$ laser beams. Since the frequency-doubling crystal angle can be fine-tuned, the energy of the two generated $532 \mathrm{~nm}$ laser beams can be adjusted according to different experimental requirements. The output laser at $532 \mathrm{~nm}$ has a repetition frequency of $30 \mathrm{~Hz}$ and $230 \mathrm{~mJ}$ of single-pulse energy, which is used to pump a pulsed dye laser 1 and produce a $589 \mathrm{~nm}$ laser with $46 \mathrm{~mJ}$ of single-pulse energy. Another $532 \mathrm{~nm}$ laser is used to pump a second pulsed dye laser 2 to produce a $770 \mathrm{~nm}$ laser. The $589 \mathrm{~nm}$ and $770 \mathrm{~nm}$ lasers divergence angle were less than 0.5 mard. Since this paper focuses on the sodium daytime detection system and its results, further explanation of the detection of the potassium has been excluded. After the $589 \mathrm{~nm}$ laser beam passed through a high power beam splitter, the main laser beam was sent to a laser beam-expanding telescope, it was directly emitted into the sky by a high power laser mirror for upper atmospheric detection, while only a small fraction was split off for laser locking. The fiber collimator was used to collect the $589 \mathrm{~nm}$ laser, it was input into to the sodium HCL. In the frequency stabilization system, there was a RC circuit, which was used to read the discharge voltage signal from the sodium HCL. The voltage is maximized when the laser is tuned to the sodium resonance transition. Therefore, by judging the voltage value, the frequency stabilization system can control the motor of the dye laser to control the wavelength of the output laser. Similarly, for a 770nm laser frequency stabilization system, the potassium HCL was used to generate voltage signal and acts as the wavelength discriminator.

The signal receiving system consists of a large aperture telescope, an optical fiber coupler, and two optical fibers. The large aperture telescope is composed of a primary and a secondary mirror, which adopts the Cassegrain-type design. The diameter and the focal length of the large aperture telescope are $1 \mathrm{~m}$ and $2 \mathrm{~m}$, respectively, and a dual-fiber focal plane splitting is placed at the receiving end of the telescope. In other words, the two optical fiber heads were placed in the focal plane of the 
receiving telescope and separated by a certain distance. By controlling the direction of the two laser beams, the high-altitude image points were able to fall directly into the incident ports of the respective optical fibers. Because the two optical fibers were separated by a certain distance and independent from each other, there was no crosstalk in space isolation. In this system, an optical fiber clamping device was installed at the focal plane of the telescope in order to fix the two receiving optical fibers in place. By using this dual-optical fiber focal plane splitting technology, the back-scattered photon signals of the $589 \mathrm{~nm}$ and $770 \mathrm{~nm}$ laser beams were coupled to their respective receiving optical fibers. These fibers consisted of hard cladded multimode quartz with a numerical aperture of 0.39 and core diameter of $1.5 \mathrm{~mm}$.

The signal detection system features two interference filters, a dual-channel FADOF, two concentrators, and two photomultiplier tubes. The received potassium signal through the collimating lens and interference filter, focused on the photomultiplier tube through the focusing lens, and then converted into the corresponding electrical signal, which was then sent to the data acquisition and timely sequence control system for further processing. After passing through the collimating lens, the sodium signal entered the dual-channel FADOF and passed through the interference filter to ensure that the background light in the day did not affect the weak return optical signal. Finally, it was converted into the corresponding electrical signal through the focusing lens, which focused on the photomultiplier tube, and entered the data acquisition and timely sequence control system. The photomultiplier tube (H7421-40 series, from Capitals for Hamamatsu Japan) features a quantum efficiency of $40 \%$ at $589 \mathrm{~nm}$.

The data acquisition and control system features an oscilloscope, a timing control system, and a central control and processing system. The electrical signals converted by the two photomultiplier tubes respectively entered the data acquisition system and were stored in the central control and processing system. The oscilloscope displayed real-time monitoring of the back-scattered photon signal, and the timing control system synchronized with the laser transmitter and data acquisition. The acquisition card is Easy-MCS with a sampling rate of $150 \mathrm{MHz}$.

The specific parameters of the lidar system are shown in the following Table 1:

Table 1. The main parameters of lidar system.

\begin{tabular}{lll}
\hline \multicolumn{1}{c}{ Laser Emission System } & Nd:YAG Laser & Na Channel \\
\hline Wavelength & $532 \mathrm{~nm}$ & $589.158 \mathrm{~nm}$ \\
Pulse energy & $230 \mathrm{~mJ}$ & $46 \mathrm{~mJ}$ \\
Repetition rate & $30 \mathrm{~Hz}$ & $30 \mathrm{~Hz}$ \\
Pulse width & $10 \mathrm{~ns}$ & $10 \mathrm{~ns}$ \\
Beam divergence & $<0.5 \mathrm{mrad}$ & $<0.5 \mathrm{mrad}$ \\
Linewidth & - & $1.5 \mathrm{GHz}$ \\
\hline \multicolumn{1}{c}{ Signal Receiving System } & \\
Telescope aperture & & $1 \mathrm{~m}$ \\
Focal length & & $2 \mathrm{~m}$ \\
Fiber diameter & & $1.5 \mathrm{~mm}$ \\
\hline \multicolumn{1}{c}{ Signal Detection System } & \\
Optical filter FWHM & & $1.0 \pm 0.2 \mathrm{~nm}$ \\
Out-of-band suppression & & $\mathrm{OD} 8(200-1200 \mathrm{~nm})$ \\
Peak transmittance & $>75 \%$ \\
Quantum efficiency of PMT & $<40 \%$ \\
Atomic filter transmittance & $>80 \%$ \\
Operating temperature of atomic filter & $>160{ }^{\circ} \mathrm{C}$ \\
Atomic filter single peak half linewidth & $0.6 \mathrm{GHz}$ \\
\hline Data Acquisition and Timing Control System & \\
Count rate & & $150 \mathrm{MHz}$ \\
Bin width & $640 \mathrm{~ns}$ \\
Bin number & 2048 \\
\hline
\end{tabular}




\section{Research and Improvement on Key Techniques of Daytime Detection}

\subsection{Daytime Detection Lidar Technology and Working Principle of FADOF}

The principle of FADOF is based on the combination of anomalous scattering, the Faraday effect, and the zeeman effect [33]. The light passes through the first polarizer, $P_{x}$ and becomes linearly polarized in the horizontal direction. This linearly polarized light can be thought of as the superposition of two equal-amplitude beams of left-handed and right-handed light, relative to the direction of the magnetic field. Under the action of the magnetic field, the phase difference between left-handed and right-handed polarized lights is caused by their different propagation speeds within the atom cell. When the two lights coming out of the atom cell are superimposed again, the polarization direction of the linearly polarized light is rotated by an angle relative to the polarization direction when incident from the $P_{x}$ plane (Figure 2). If this angle happens to be an odd number of 90 degrees, then the combined linearly polarized light is vertical, and it can be seen through the second polarizer $P_{y}$.

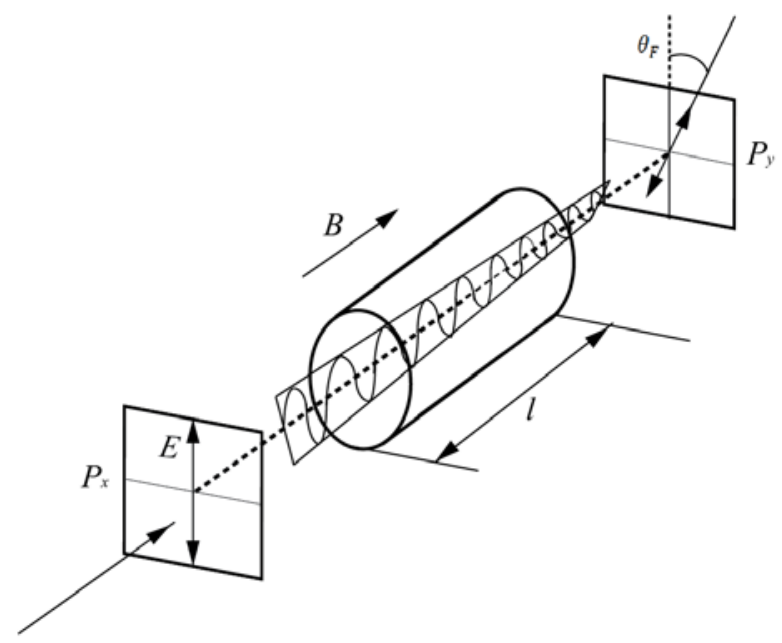

Figure 2. Faraday effect schematic.

In this system, the FADOF consists of a sodium atom cell in a longitudinal magnetic field, a constant temperature furnace, and a pair of Glan-Thompson type orthogonal polarization prisms at both ends with an inhibition rate of about $10^{-5}$ [34]. The magnetic field is generated by a permanent magnet with a strength of approximately $0.2 \mathrm{~T}$. The length of the sodium atom cell is $20 \mathrm{~mm}$, and the constant temperature is $160^{\circ} \mathrm{C}$, which, if adjusted within $50-200{ }^{\circ} \mathrm{C}$, can maintain accuracy of better than $0.5 \%$. During the orthogonal polarization, consider that the unpolarized light incident from the left consists of the combination of the $\mathrm{D}_{2}$ resonant laser of the sodium atom $(588.995 \mathrm{~nm})$ and the broad band of the solar background light. Since the wavelength of most broadband background light cannot resonate with the transition energy level of the sodium atom in the cell, it becomes blocked by the orthogonal polarization prism. The $\mathrm{D}_{2}$ resonance light of the sodium atom (including a very small part of the background light with the same wavelength) can resonate with the level of the sodium atom in the cell and, under the appropriate longitudinal magnetic field and constant temperature setting, can rotate the wavelength of the laser in the cell polarization 90 degrees (or its odd times), so that the sodium fluorescence can pass smoothly through the second polarization prism, thus being efficiently transmitted by the FADOF.

\subsection{Improved Optical Path Technology for Daytime Detection of Atomic Filters}

The diurnal observation of sodium lidar system at Yanqing was performed through the joint efforts of the NSSC and WIPM. The main improvement of the FADOF system is an upgrade of the original single FADOF to a dual-channel FADOF. 
The dual-wavelength lidar structure schematic diagram is shown in Figure 1. In a signal receiving and detection system, the sodium back-scattered photon singal received by the telescope through the optical fiber into the FADOF, at this time, due to the fiber's depolarization effects, reduces transmissivity of the FADOF by about half, greatly reducing the signal strength and the SNR. In the diurnal sodium fluorescence lidar system at Yanqing, two identical FADOFs are used in the receiving channel to receive various polarization components in the back-scattered photon signal, respectively, and increase the signal intensity. The optical circuit schematic and physical diagram are shown in Figures 3 and 4 below.

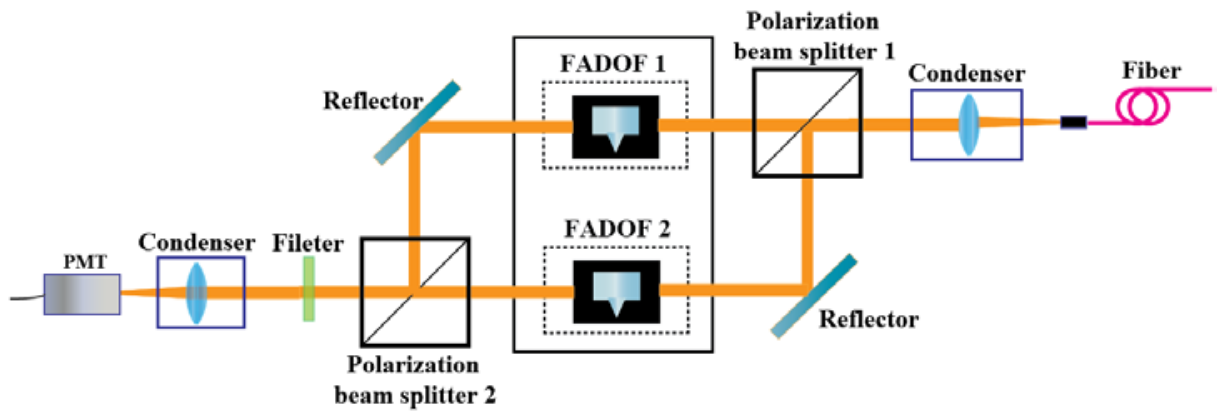

Figure 3. Optical path schematic of the dual -channel FADOF.

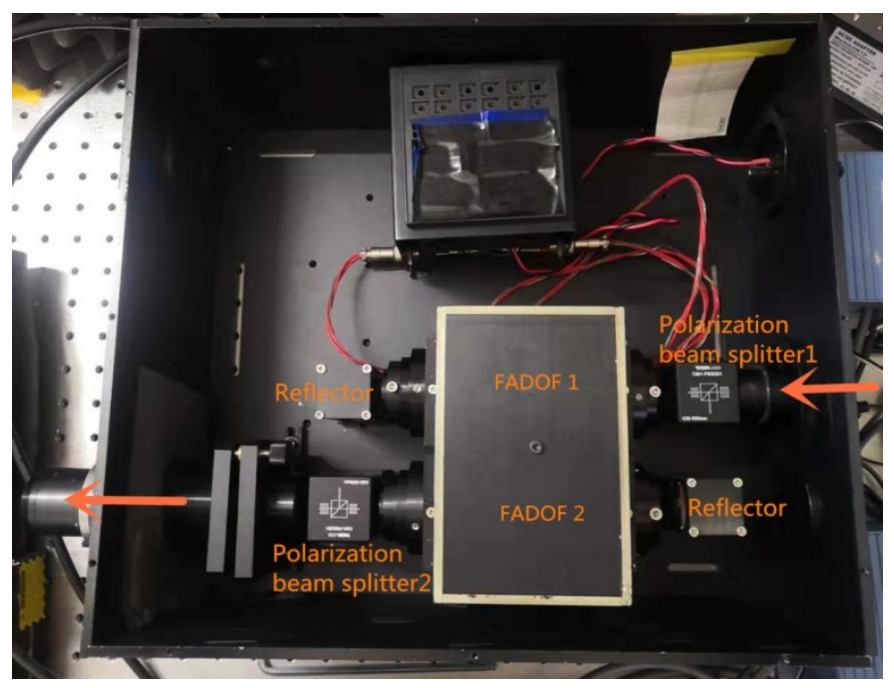

Figure 4. Dual-channel FADOF physical diagram.

The back-scattered photon signal received by the optical fiber is collimated through the focusing system and enters the first polarization beam splitter to separate the signal light of different polarization states. The transmitted signal enters the first FADOF, and the reflected signal enters the second FADOF through the laser mirror. In this process, while the wavelength of most broadband background light is not able to resonate with the transition level of the atoms in the FADOF, the narrow band resonance fluorescence is able to resonate and therefore generate Faraday rotation of the polarization plane, so the polarization states of the signals passing through the two FADOFs are exactly opposite. The signal passing through the first FADOF is reflected from the laser mirror to the second polarization beam splitter, then reflected to the focusing lens, and then enters the photomultiplier. The signal passing through the second FADOF is transmitted to the condenser through the second polarization beam splitter and enters the photomultiplier tube. At this time, the backscattered signal received by the optical receiving system is collected by the photomultiplier tube in preparation for the next. For dual-channel FADOF, some tests have been done by Yang [28] with a potassium cell. Since the potassium FADOF works in the same way as the sodium FADOF, we can learn something from this test. In the experiment, firstly, a laser beam incident into dual-channel FADOF, a laser absorber was 
used to block any channel of a dual-channel FADOF separately, and a detector was used to measure the light energy of each channel respectively and convert them into the voltage value at the same time. The results showed that the voltage of the two channels were basically the same. Secondly, we removed the absorber and opened both channels; the voltage was nearly twice that of a single channel. These results show that the two polarization components of the signal light can pass through the dual-channel FADOF at the same time, and the improvement of efficiency of dual-channel FADOF to one FADOF was $84.5 \%$.

\subsection{Research and Improvement of Other Key Technologies}

This daytime detection system offers not only improved the efficiency of the FADOF, but also upgrades additional other technologies of the laser linewidth of the laser emission system and optical fiber transmittance of the signal receiving system.

In the laser emission system, the internal grating of the pulsed dye laser was changed from single grating to double grating. In the case of single grating, the output laser linewidth is $0.08 \mathrm{~cm}^{-1}$. After changing to double grating, the laser linewidth is $0.05 \mathrm{~cm}^{-1}$, which is more conducive to the detection of sodium atoms. According to the inversion equation of lidar, the effective scattering cross section of metal atom ions is an important parameter, the narrow linewidth laser detection is beneficial to increase the effective scattering cross section. At the peak of metal atom ion density, the effective scattering cross section depends on the linewidth of the laser; therefore, the narrower the laser linewidth, the larger the effective scattering cross section. Moreover, within a certain range of linewidth (narrower linewidth causes the metal layer to saturate), the larger the effective scattering cross section and the higher the density of metal atoms detected. This allowed for more photons of the returned signal to be obtained and improved the SNR. In the signal receiving system, the optical fiber was replaced. After the upgrade of the optical fiber core material for high refractive index of the quartz glass, the attenuation degree at $589 \mathrm{~nm}$ was improved from $250-400 \mathrm{~dB} / \mathrm{km}$ to $15 \mathrm{~dB} / \mathrm{km}$, and the core diameter was reduced from $2 \mathrm{~mm}$ to $1.5 \mathrm{~mm}$, therefore greatly improving the transmittance of the receiving system. Moreover, under the same receiving telescope, the smaller diameter of the optical fiber now reduces the received field of view of the lidar which further decreases the influence of the spatial background light, and also contributes to improving the SNR.

In other aspects, the total combined effect of effective transceiver matching and alignment technology, optical path collimation technology, and strict light avoidance treatment on the whole receiving channel, results in better detection signal quality overall.

\section{Analysis of Daytime Observations}

\subsection{Statistics of Continuous Observation Duration}

The diurnal sodium fluorescence lidar system at Beijing Yanqing station was completed in April 2014 and thereafter operated in clear weather and the dual-channel FADOF remained in the signal detection system through the whole operation. During the observation period from April 2014 to July 2017, there were 103 cases of continuous daytime observation, totaling $4870 \mathrm{~h}$. The duration of each observation is shown in Figure 5. Of these, there were 71 cases with observation time exceeding $24 \mathrm{~h}$, 33 cases exceeding 48 h, 18 cases exceeding 72 h, 10 cases exceeding 96 h, and 4 cases exceeding $120 \mathrm{~h}$; the longest observation time reached $181 \mathrm{~h}$. 


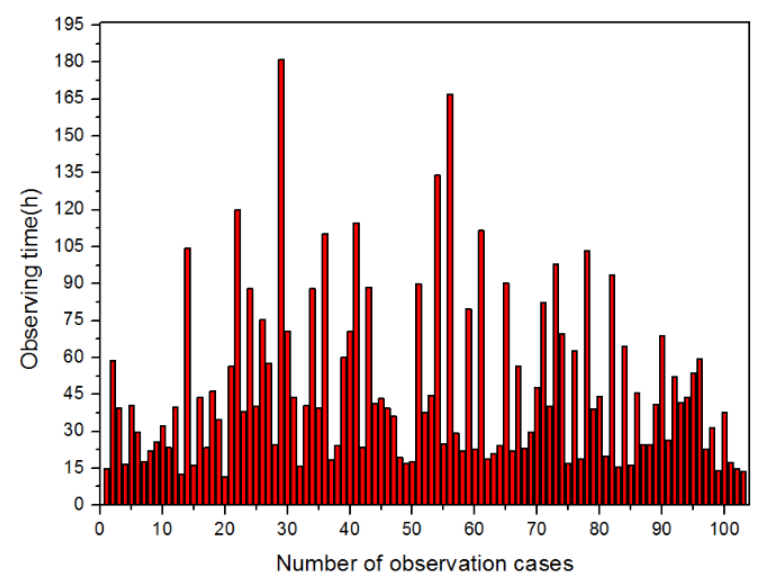

Figure 5. Statistics of continuous observation duration from April 2014 to July 2017.

\subsection{Detection Results}

Figure 6 presents the original back-scattered photo of sodium lidar at 12:24 Local Time on 16 October 2014, in which the spatial resolution was $96 \mathrm{~m}$ and the temporal resolution was $2.8 \mathrm{~min}$. The background photon number was approximately 75, with 1466 signal photons, and the SNR reached 19:1. Compared with the detection results of the first FADOF developed by WIPM, which had a time resolution of $2.8 \mathrm{~min}$, spatial resolution of $200 \mathrm{~m}$, and a SNR of 1 2, this diurnal sodium fluorescence lidar system has reduced the background light noise, greatly improved the SNR, and achieved long-term continuous observation.

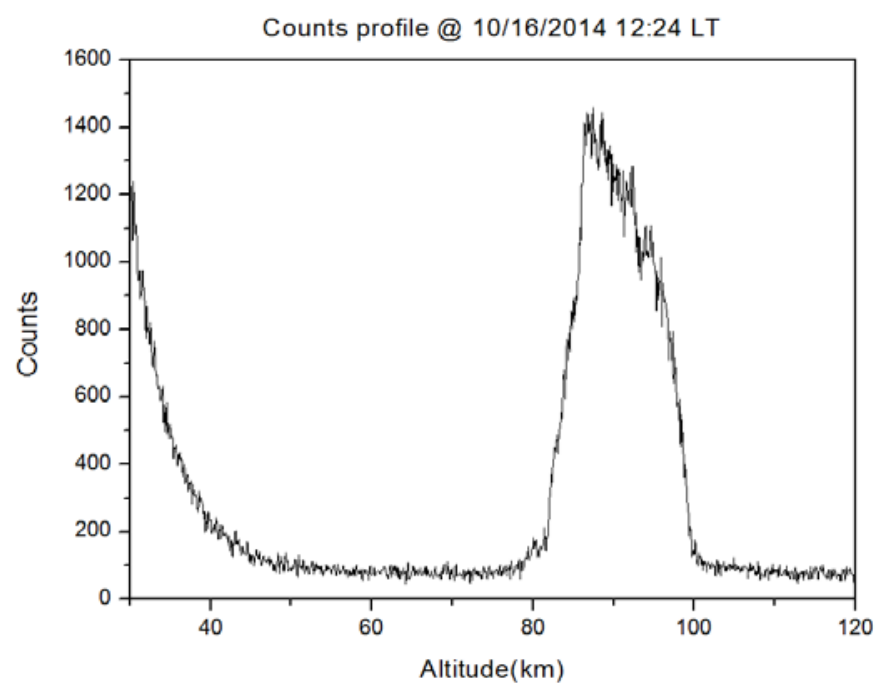

Figure 6. Original back-scattered photo data observed by sodium lidar during the daytime.

Figure 7 shows the continuous diurnal variation of the sodium layer at Beijing Yanqing lidar station from 13 October, to 18 October 2014. The observation lasted up to $120 \mathrm{~h}$ and covered five complete diurnal cycles of the sodium layer. It shows that the sodium layer structure varied with LT periodically, with maximum of sodium density near $87,93,95,90$, and $88 \mathrm{~km}$. It shows a $24 \mathrm{~h}$ periodic fluctuation in the diurnal variation of sodium layer density [35]. 


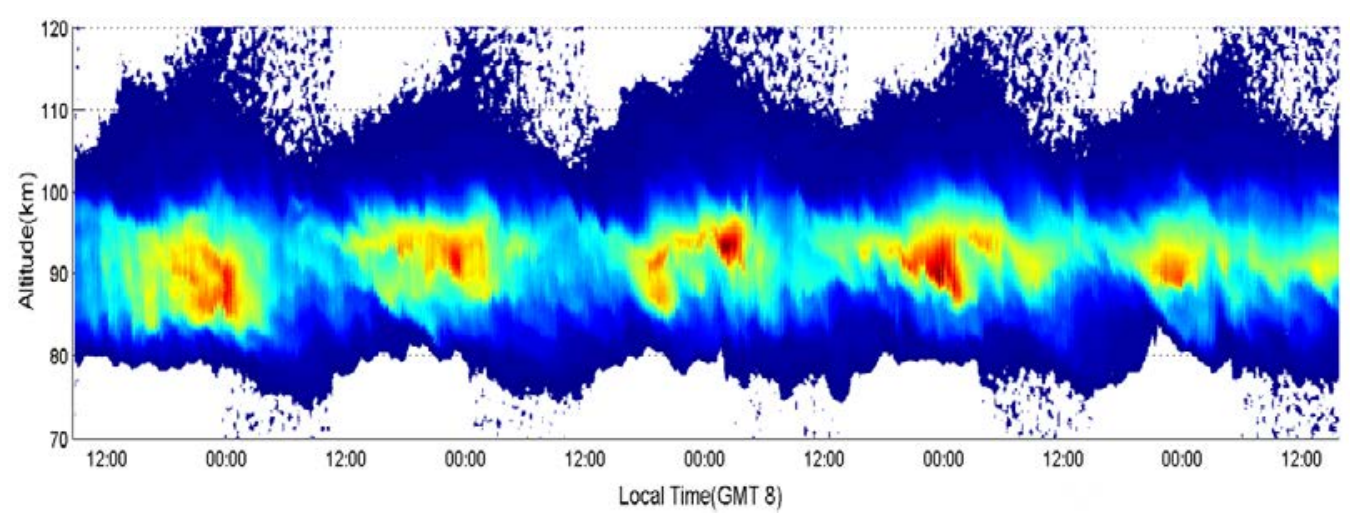

Figure 7. Five complete diurnal cycles of observation by sodium lidar at Beijing Yanqing lidar station.

According to these observations, the sodium atomic density and width of the sodium layer both decreased during the day. This was also noted in Illinois $\left(40^{\circ} \mathrm{N}, 88^{\circ} \mathrm{W}\right)$, by States et al. [36], who stated that this may have been due to the influence of photoionization effect, which causes atoms to be ionized by sunlight in the daytime. At the Colorado State University (CSU) Fort Collins ( $41^{\circ} \mathrm{N}, 105^{\circ} \mathrm{W}$ ), the sodium lidar system conducted a 9-day continuous campaign between UT day 264 and 272 during September 2003. This unusually long data set revealed a dramatically noticeable short-term tidal variability, with a substantial temperature inversion accompanied by strong wind shear on day 267, coupled with planetary wave activities [37]. During this observation period, the potential temperature contours show a strong modulation of the sodium layer. There is reasonable agreement between the movement of potential temperature and sodium contours in the bottom side of the sodium layer [38]. In 2012, Yuan et al. [39] observed strong tidal variability of the sodium layer, and explained that the reason for the layer's low density may have been because the $\mathrm{NaHCO}_{3}$ to atomic sodium relationship has a strong positive correlation with in-situ temperature, thus the cold temperature in the mesopause region induces a much smaller sodium abundance. They also mentioned a possible modulation mechanism by tide, in that the large tidal variability was may have been caused by tide-gravity wave interaction and planetary wave modulation. In 2017, Cai et al. [40] provided a numerical simulation on the variation of sodium layer and demonstrated the influence of tide and chemistry on the layer's diurnal variation.

\subsection{Sporadic Sodium Layer During the Daytime}

Several times during full-diurnal cycle observation, a phenomenon, known as the sporadic sodium layer (Nas), was observed during the day. Figure 8 shows the unique and rare evolution of the density profile of the sodium layer with time and altitude from 2 November to 5 November 2014, featuring a total continuous observation duration of $87.9 \mathrm{~h}$, time resolution of $16.7 \mathrm{~min}$, and spatial resolution of $96 \mathrm{~m}$. Additionally, on 3 and 4 November, two consecutive Nas events were emergent during the day (Figure 8a, black box), and demonstrated the evolution process of its breaking form (Figure 8b,c). On 4 November, the Nas lasted until November 5 at 6:30 LT in the morning. Among them, on 3 November 2014, the duration of Nas ranged from 13:51 LT to 19:16 LT, and the peak density of this event reached its maximum at 15:50 LT (approximately 10,126 $\mathrm{cm}^{-3}$ ), and the corresponding peak altitude was $94 \mathrm{~km}$. The ascending time was $120 \mathrm{~min}$, the descending time was $206 \mathrm{~min}$, and the descent speed of the Nas' layer was $0.32 \mathrm{~m} / \mathrm{s}$. In this case, the ascending time was less than the descending time. On 4 November, the duration of Nas ranged from 14:47 LT to 16:50 LT, and the peak density of this event reached its maximum at 16:16 LT. The peak density was $8445 \mathrm{~cm}^{-3}$, and the corresponding peak altitude was $94 \mathrm{~km}$. The Nas event on 4 November featured a longer, ascending time of $89 \mathrm{~min}$, a shorted descending time of $34 \mathrm{~min}$, and a descent speed of $0.23 \mathrm{~m} / \mathrm{s}$. 


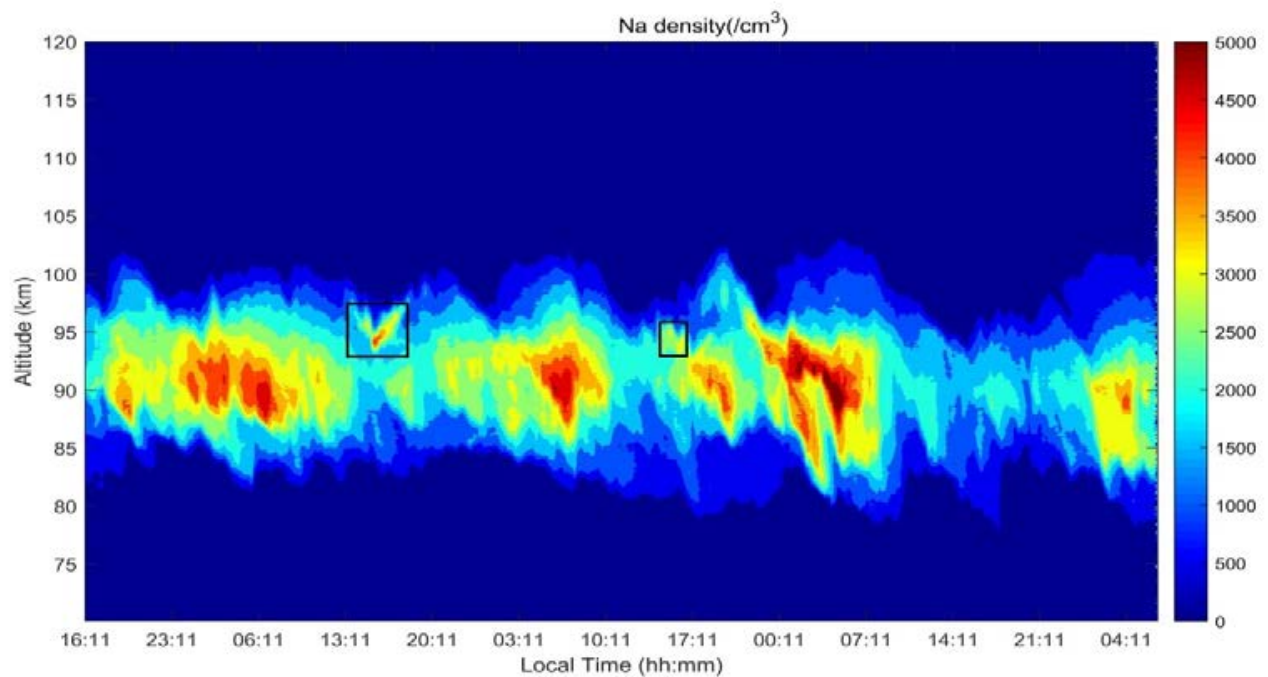

(a)

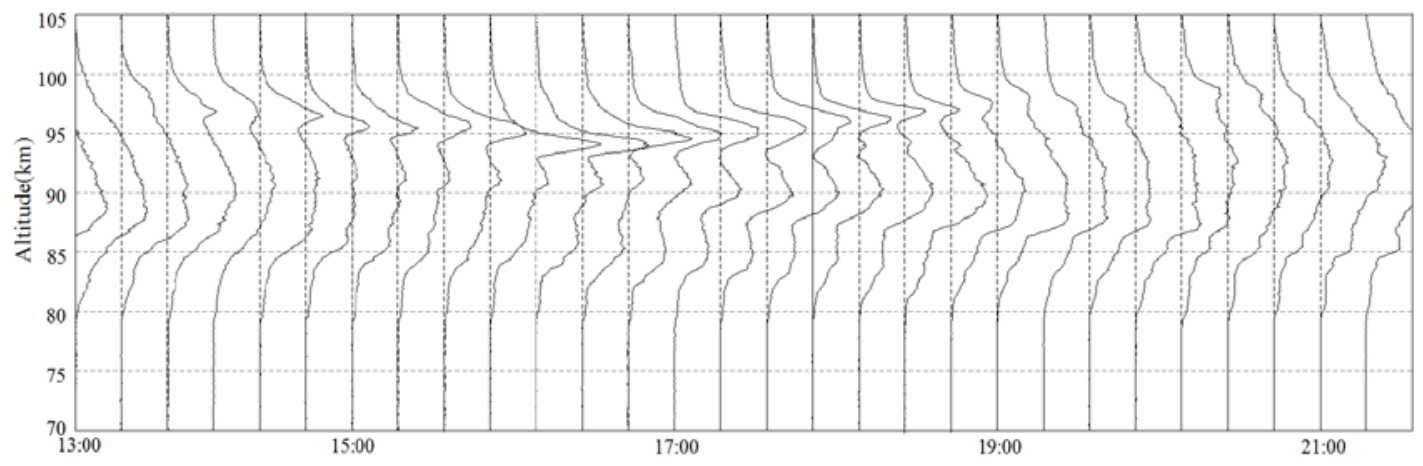

(b) LT

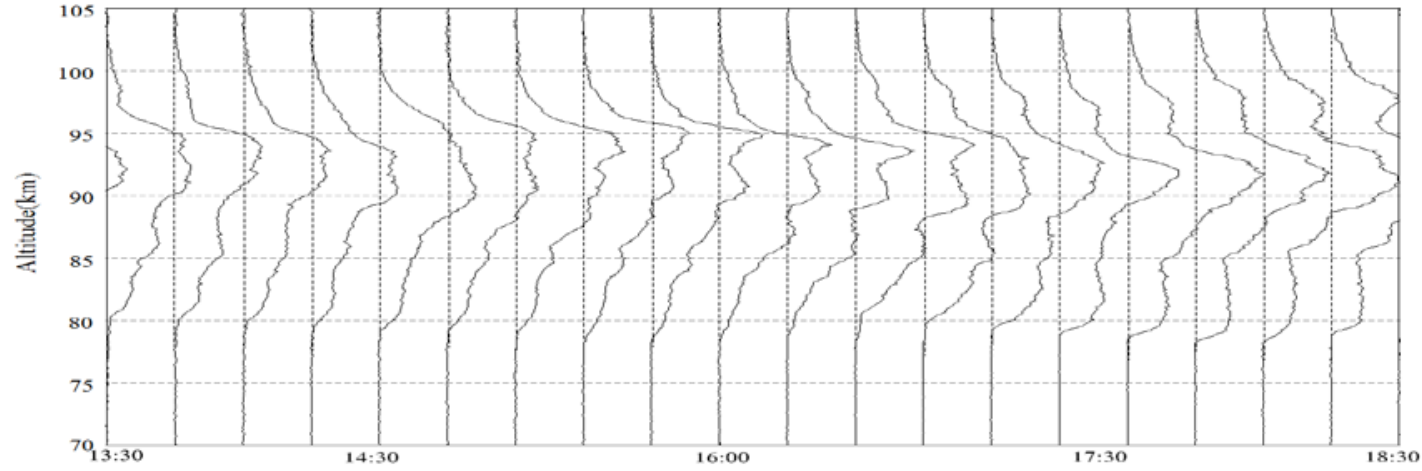

(c) ${ }^{\mathrm{LT}}$

Figure 8. (a) The evolution of the density profile $2-5$ November 2014. (b) The evolution detail of a Nas event at 3 November 2014. (c) The evolution detail of a Nas event at 4 November 2014.

Several lidar observations of Nas at different locations were performed in daytime. In 2014, Yuan et al. [41] provided the first study on the diurnal distribution of Nas based on diurnal observation of sodium lidar in Utah State University (USU). In 2017, Cai et al. provide a numerical investigation on diurnal variation of sodium layer in the summer over USU, and proposed a possible mechanism for contributing to the formation of Nas-namely, the vertical transport by wind. In 2019, Cai et al. [42] utilized a two-dimensional numerical model simulations, to investigate the mechanism that drives such summer winter difference of the Nas occurrence rate in the middle latitude. The observation of these phenomena is beneficial to the study of the characteristics of the atmospheric metal layer [43,44]. In addition, the Yanqing station also has a sodium wind temperature lidar [45], which can be combined 
with high-resolution temperature and wind data, and thus be more conducive to exploring the formation mechanism of Nas.

\section{Conclusions}

In this study, a diurnal sodium fluorescence lidar system was adopted that employed dual-channel FADOF technology and combines contemporary laser technology and with lidar detection technology to obtain a sodium layer with high signal quality in the daytime at Beijing Yanqing station. This system realized the continuous diurnal detection capability and extended the time scope of detection data to improve upon past capabilities limited only to night-time detection. This lidar system operated from April 2014 to July 2017, and the continuous detection time with daytime detection data over $4870 \mathrm{~h}$. Among these observation data, the longest continuous observation time reached $181 \mathrm{~h}$ and the SNR was up to 19:1 at noon in the daytime. Several instances of Nas were also observed during the day and the corresponding peak altitude was $94 \mathrm{~km}$. Previous research also reported that the Nas event's duration was 1-3 h at night, while our research observed Nas during the day lasting for $5.4 \mathrm{~h}$, which is much longer. In the Nas event of 3 November, the ascending time was less than the descending time, contrastingly another Nas event on 4 November, the ascending time was longer. This result is different from previous reports that the descending time of Nas at night in Beijing was generally longer than the ascending time [46]. Regarding interpretations of diurnal variation of the sodium layer, there are also different views, some reported that the diurnal cycle of the sodium layer are driven by a solar diurnal or semidiurnal variation tendency, especially, She et al. [37] notes that there is a significant semidiurnal component noted in the observations at Fort Collins $\left(41^{\circ} \mathrm{N}, 105^{\circ} \mathrm{W}\right)$. Other observations support the opinion that $\mathrm{Na}$ density variations are mostly due to the changing of photochemistry reaction, such as States et al. [36] found that Na density decreases monotonically from sunrise until sunset and then increases monotonically from sunset until sunrise in Illinois $\left(40^{\circ} \mathrm{N}, 88^{\circ} \mathrm{W}\right)$. It seems that the description of $\mathrm{Na}$ density features have yet to be further research, so it is meaningful to obtain continuous detection results both during the day and night to analyze the characteristics and modulation of diurnal variation of sodium layer in the daytime.

Author Contributions: Conceptualization, X.C.; data curation: J.W., F.L., S.G., Y.Y. and H.Z.; formal analysis, L.D. and Y.X.; funding acquisition, G.Y.; investigation, L.D., J.W., H.Z., X.C., and G.Y.; project administration, G.Y.; methodology, L.D.; resources, G.Y. and J.W.; software, L.D., F.W. and Z.L.; validation, X.C., J.W., H.Z., F.L., S.G. and Y.Y.; writing—original draft preparation, L.D.; writing—review and editing, F.W., and Y.X. All authors have read and agreed to the published version of the manuscript.

Funding: This research was funded by the Natural Science Foundation of China, grant number 41627804, and the research was funded by Specialized Research fund for State Key Laboratories of China.

Acknowledgments: We sincerely acknowledge for the technical support provided by WIPM in lidar dual-channel FADOF technology, and acknowledge Meridian Space Weather Monitoring Project and Data Centre for Meridian Space Weather Monitoring Project providing the equipment and data.

Conflicts of Interest: The authors declare no conflict of interest.

\section{References}

1. Clemesha, B.R.; Batista, P.P.; Simonich, D.M.; Batista, I.S. Sporadic structures in the atmospheric sodium layer. J. Geophys. Res. Atmos. 2003, 109. [CrossRef]

2. Gardner, C.S. Sodium resonance fluorescence lidar applications in atmospheric science and astronomy. Proc. IEEE 1989, 77, 408-418. [CrossRef]

3. Plane, J.M.; Gardner, C.S.; Yu, J.; She, C.Y.; Garcia, R.R.; Pumphrey, H.C. Mesospheric Na layer at $40{ }^{\circ}$ N: Modeling and observations. J. Geophys. Res. 1999, 104, 3773-3788. [CrossRef]

4. Kane, T.J.; Hostetler, C.A.; Gardner, C.S. Horizonal and vertical structure of the major sporadic sodium layer events observed during ALOHA-90. Geophys. Res. Lett. 1991, 18, 1365-1368. [CrossRef]

5. Fan, Z.Y.; Plane, J.M.; Gumbel, J. On the global distribution of sporadic sodium layers. Geophys. Res. Lett. 2007, 34, 030542. [CrossRef] 
6. Chu, X.; Papen, G.C. Resonance fluorescence lidar for measurements of the middle and upper atmosphere. Laser Remote Sens. 2005, 97, 235-240.

7. Ejiri, M.K.; Nakamura, T.; Kawahara, T.D. Seasonal variation of nocturnal temperature and sodium density in the mesopause region observed by a resonance scatter lidar over Uji, Japan. J. Geophys. Res. 2010, 115, D18126. [CrossRef]

8. Nozawa, S.; Kawahara, T.D.; Saito, N.; Hall, C.M.; Tsuda, T.T.; Kawabata, T.; Wada, S.; Brekke, A.; Takahashi, T.; Fujiwara, H.; et al. Variations of the neutral temperature and sodium density between 80 and $107 \mathrm{~km}$ above Tromsø during the winter of 2010-2011 by a new solid-state sodium lidar. J. Geophys. Res. 2014, 119, 441-451. [CrossRef]

9. Yuan, T.; She, C.Y.; Hagan, M.E.; Williams, B.P.; Li, T.; Arnold, K.; Kawahara, T.D.; Acott, P.E.; Vance, J.D.; Krueger, D.; et al. Roble. Seasonal variation of diurnal perturbations in mesopause region temperature, zonal, and meridional winds above fort collins, colorado $\left(40.6^{\circ} \mathrm{N}, 105^{\circ} \mathrm{W}\right)$. J. Geophys. Res. Atmos. 2006, 111, D06103. [CrossRef]

10. Yuan, T.; She, C.Y.; Krueger, D.A.; Sassi, F.; Garcia, R.; Roble, R.G.; Liu, H.L.; Schmidt, H. Climatology of mesopause region temperature, zonal wind, and meridional wind over Fort Collins, Colorado $\left(41^{\circ} \mathrm{N}, 105^{\circ}\right.$ W), and comparison with model simulations. J. Geophys. Res. 2008, 113, D03105. [CrossRef]

11. Krueger, D.A.; She, C.Y.; Yuan, T. Retrieving mesopause temperature and line-of-sight wind from full-diurnal-cycle Na lidar observations. Appl. Opt. 2015, 54, 9469-9489. [CrossRef]

12. Clemesha, B.R.; Simonich, D.M.; Batista, P.P.; Takahashi, H. Seasonal variation in the solar diurnal tide and its possible influence on the atmospheric sodium layer. Adv. Space Res. 2005, 35, 1951-1956. [CrossRef]

13. Clemesha, B.R.; Simonich, D.M.; Batista, P.P.; Kirchhoff, V.W.J.H. The Diurnal Variation of Atmospheric Sodium. J. Geophys. Res. 1982, 87, 181-186. [CrossRef]

14. Kwon, K.H.; Gardner, C.S.; Senf, D.C. Daytime Lidar Measurements of Tidal Winds in the Mesospheric Sodium Layer at Urbana, Illinois. J. Geophys. Res. 1987, 92, 8781-8786. [CrossRef]

15. Gelbwachs, J.A. Atomic resonance filter. IEEE J. Quantum Electron. 1988, 24, 1266-1277. [CrossRef]

16. Yin, B.; Shay, T.M. Theoretical model for a Faraday anomalous dispersion optical filter. Opt. Lett. 1991, 16, 1617-1619. [CrossRef]

17. Chen, H.; White, M.A.; Krueger, D.A.; She, C.Y. Daytime mesopause temperature measurements with a sodium-vapor dispersive Faraday filter in a lidar receiver. Opt. Lett. 1996, 21, 1093-1095. [CrossRef]

18. Chen, S.; Hu, Z.; White, M.A.; Chen, H.; Krueger, D.A.; She, C.Y. Lidar observations of seasonal variation of diurnal mean temperature in the mesopause region over Fort Collins, Colorado $\left(41^{\circ} \mathrm{N}, 105^{\circ} \mathrm{W}\right)$. J. Geophys. Res. 2000, 105, 12371-12379. [CrossRef]

19. She, C.Y.; Sherman, J.; Yuan, T.; Williams, B.P.; Arnold, K.; Kawahara, T.D.; Li, T.; Xu, L.F.; Vance, J.D.; Acott, P.; et al. The first 80-hour continuous lidar campaign for simultaneous observation of mesopause region temperature and wind. Geophys. Res. Lett. 2003, 30. [CrossRef]

20. Li, T.; She, C.Y.; Liu, H.L.; Leblanc, T.; McDermid, I.S. Sodium lidar-observed strong inertia-gravity wave activities in the mesopause region over Fort Collins, Colorado $\left(41^{\circ} \mathrm{N}, 105^{\circ} \mathrm{W}\right)$. J. Geophys. Res. 2007, 112. [CrossRef]

21. Yuan, T.; Schmidt, H.; She, C.Y.; Krueger, D.A.; Reising, S. Seasonal variations of semidiurnal tidal perturbations in mesopause region temperature and zonal and meridional winds above Fort Collins, Colorado $\left(40.6^{\circ} \mathrm{N}, 105.1^{\circ} \mathrm{W}\right)$. J. Geophys. Res. 2008, 113. [CrossRef]

22. Li, T.; She, C.Y.; Liu, H.L.; Yue, J.; Nakamura, T.; Krueger, D.A.; Wu, Q.; Dou, X.; Wang, S. Observation of local tidal variability and instability, along with dissipation of diurnal tidal harmonics in the mesopause region over Fort Collins, Colorado $\left(41^{\circ} \mathrm{N}, 105^{\circ} \mathrm{W}\right)$. J. Geophys. Res. 2009, 114, D06106. [CrossRef]

23. Cai, X.; Yuan, T.; Zhao, Y.; Pautet, P.D.; Taylor, M.J.; Pendleton, W.R., Jr. A coordinated investigation of the gravity wave breaking and the associated dynamical instability by a Na lidar and an Advanced Mesosphere Temperature Mapper over Logan, UT (41.7 N, 111.8 W). J. Geophys. Res. Space Phys. 2014, 119, 6852-6864. [CrossRef]

24. Gong, S.; Cheng, X.; Li, F.; Yang, G.; Yang, Y.; Wang, J. Applications of Atomic Spectra Filtering and Atomic Frequency Discrimination in Optoelectronic Systems. Laser Optoelectron. Prog. 2010, 47, 42301-42307. [CrossRef] 
25. Hu, Z.; Sun, X.; Liu, Y.; Fu, L.; Zeng, X. Temperature properties of Na dispersive Faraday optical filter at $\mathrm{D}_{1}$ and $\mathrm{D}_{2}$ line. Opt. Commun. 1998, 156, 289-293. [CrossRef]

26. Li, F.; Lin, X.; Cheng, X.; Yang, Y.; Wu, K.; Gong, S. A Doppler lidar with atomic Faraday devices frequency stabilization and discrimination. Chin. J. Quantum Electron. 2013, 30, 42-45. [CrossRef]

27. Yang, Y.; Cheng, X.; Dou, X.; Gong, J.; Rao, C.; Xiong, J.; Xia, Y.; Li, Y.; Li, F.; Lin, X.; et al. Hyperspectral solar observation based on the sodium atomic filter. Sci. Sin. 2016, 46, 69602-69606.

28. Yang, Y. Atomic Frequency Discriminator and its Application in Solar Observation. Ph.D. Thesis, Wuhan Institute of Physics and Mathematics, Chinese Academy of Sciences, Wuhan, China, 5 March 2013.

29. Cheng, X.; Yang, Y.; Wang, Z.; Li, F.; Yang, G.; Zhao, Z.; Gong, W.; Wang, J.; Hu, X.; Lin, X.; et al. Joint observation results of Na layer and ionosphere in Wuhan during the Total Solar Eclipse. Sci. China 2015, 45, 1569-1574. [CrossRef]

30. Cheng, X.; Gong, S.; Li, F. Daytime Observation Technology of Lidar by Using Atomic Optical Filer. Chin. J. Lasers 2007, 34, 406-410.

31. Cheng, X.; Gong, S.; Li, F.; Dai, Y.; Song, J.; Wang, J.; Li, F. 24 h continuous observation of sodium layer over Wuhan by lidar. Sci. Ser. G 2007, 50, 287-293. [CrossRef]

32. Wang, Z.; Yang, G.; Wang, J.; Yue, C.; Yang, Y.; Jiao, J.; Du, L.; Cheng, X.; Chi, W. Seasonal variations of

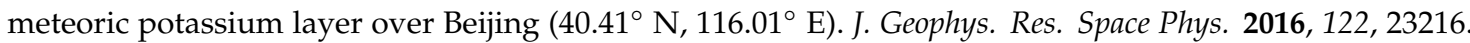
[CrossRef]

33. Harrell, S.D.; She, C.Y.; Yuan, T.; Krueger, D.A.; Chen, H.; Chen, S.S.; Hu, Z.L. Sodium and potassium vapor Faraday filters revisited: Theory and applications. J. Opt. Soc. Am. B Opt. Phys. 2009, 26, 659-670. [CrossRef]

34. Cheng, X.W.; Li, F.Q.; Lin, Z.X. Properties and applications of Faraday Anomalous Dispersion Optical Filter. Opt. Optoelectron. Technol. 2003, 1, 41-43.

35. Gong, S.; Yang, G.; Cheng, X.; Gong, S.; Xu, J.; Li, F.; Gong, W.; Wang, J. Lidar observation campaigns on diurnal variations of the sodium layer in Beijing and Wuhan, China. Sci. China Earth Sci. 2015, 58, 1-10. [CrossRef]

36. States, R.; Gardner, C.S. Structure of the mesospheric Na layer at $40^{\circ} \mathrm{N}$ latitude: Seasonal and diurnal variations. J. Geophys. Res. 1999, 104, 3881-3888. [CrossRef]

37. She, C.Y.; Li, T.; Collins, R.L.; Yuan, T.; Williams, B.P.; Kawahara, T.D.; Vance, J.D.; Acott, P.; Krueger, D.A.; Liu, H.L.; et al. Tidal perturbations and variability in mesopause region over Fort Collins, $\mathrm{CO}\left(41^{\circ} \mathrm{N}, 105^{\circ} \mathrm{W}\right)$ : Continuous multi-day temperature and wind lidar observations. Geophys. Res. Lett. 2004, 31, L24111. [CrossRef]

38. Xu, J.; Smith, A.K.; Collins, R.L.; She, C.Y. Signature of an overturning gravity wave in the mesospheric sodium layer: Comparison of a nonlinear photochemical-dynamical model and lidar observations. J. Geophys. Res. 2006, 111. [CrossRef]

39. Yuan, T.; She, C.Y.; Kawahara, T.D.; Krueger, D.A. Variations of midlatitude mesospheric Na layer and their tidal period perturbations based on full diurnal cycle Na lidar observations of 2002-2008. J. Geophys. Res. 2012, 117. [CrossRef]

40. Cai, X.; Yuan, T.; Eccles, J.V. A numerical investigation on tidal and gravity wave contributions to the summer time Na variations in the midlatitude E region. J. Geophys. Res. Space Phys. 2017, 122, 10577-10595. [CrossRef]

41. Yuan, T.; Wang, J.; Cai, X.; Sojka, J.; Rice, D.; Oberheide, J.; Criddle, N. Investigation of the seasonal and local time variations of the high-altitude sporadic Na layer (Nas) formation and the associated midlatitude descending E layer (Es) in lower E region. J. Geophys. Res. Space Phys. 2014, 119, 5985-5999. [CrossRef]

42. Cai, X.; Yuan, T.; Eccles, J.V.; Raizada, S. Investigation on the distinct nocturnal secondary sodium layer behavior above $95 \mathrm{~km}$ in winter and summer over Logan, UT $\left(41.7^{\circ} \mathrm{N}, 112^{\circ} \mathrm{W}\right)$ and Arecibo Observatory, PR $\left(18.3^{\circ} \mathrm{N}, 67^{\circ} \mathrm{W}\right)$. J. Geophys. Res. Space Phys. 2019, 124, 9610-9625. [CrossRef]

43. Wang, J.; Yang, Y.; Cheng, X.; Yang, G.; Song, S.; Gong, S. Double sodium layers observation over Beijing, China. Geophys. Res. Lett. 2012, 39, L15801. [CrossRef]

44. Jiao, J.; Yang, G.; Zou, X.; Gong, S.; Wang, J.; Tian, D.; Cheng, X. Joint observations of sporadic sodium and sporadic E layers at middle and low latitudes in China. Chin. Sci. Bull. 2014, 59, 3868-3876. [CrossRef] 
45. Xia, Y.; Du, L.; Cheng, X.; Li, F.; Wang, J.; Wang, Z.; Yang, Y.; Lin, X.; Xun, Y.; Gong, S.; et al. Development of a solid-state sodium Doppler lidar using an all-fiber-coupled injection seeding unit for simultaneous temperature and wind measurements in the mesopause region. Opt. Express 2017, 25, 5264-5278. [CrossRef] [PubMed]

46. Jiao, J.; Yang, G.; Wang, J.; Cheng, X.; Li, F.; Yang, Y.; Gong, W.; Wang, Z.; Du, L.; Yan, C.; et al. First report of sporadic K layers and comparison with sporadic Na layers at Beijing, China (40.6 $\left.{ }^{\circ} \mathrm{N}, 116.2^{\circ} \mathrm{E}\right)$. J. Geophys. Res. Space Phys. 2015, 120, 5214-5225. [CrossRef]

(C) 2020 by the authors. Licensee MDPI, Basel, Switzerland. This article is an open access article distributed under the terms and conditions of the Creative Commons Attribution (CC BY) license (http://creativecommons.org/licenses/by/4.0/). 